\title{
Behavioral and biochemical evidence of the role of acetaldehyde in the motivational effects of ethanol
}

\author{
Alessandra T. Peana ${ }^{1 *}$ and Elio Acquas ${ }^{2 *}$ \\ Department of Chemistry and Pharmacy, University of Sassari, Sassari, Italy \\ ${ }^{2}$ Department of Life and Environmental Sciences - Pharmaceutical, Pharmacological and Nutraceutical Sciences Section, University of Cagliari, Cagliari, Italy
}

\author{
Edited by: \\ John D. Salamone, University of \\ Connecticut, USA \\ Reviewed by: \\ Merce Correa, Universitat Jaume I, \\ Spain \\ Laura F. Hurtado, Universitat \\ Jaume I, Spain \\ *Correspondence: \\ Elio Acquas, Department of Life \\ and Environmental Sciences - \\ Pharmaceutical, Pharmacological \\ and Nutraceutical Sciences Section, \\ University of Cagliari, via Ospedale, \\ 72 - I-09124 Cagliari, Italy \\ e-mail: acquas@unica.it; \\ Alessandra T. Peana, Department of \\ Chemistry and Pharmacy, University \\ of Sassari, Sassari, Italy \\ e-mail: apeana@uniss.it
}

Since Chevens' report, in the early 50's that his patients under treatment with the aldehyde dehydrogenase inhibitor, antabuse, could experience beneficial effects when drinking small volumes of alcoholic beverages, the role of acetaldehyde (ACD) in the effects of ethanol has been thoroughly investigated on pre-clinical grounds. Thus, after more than 25 years of intense research, a large number of studies have been published on the motivational properties of ACD itself as well as on the role that ethanol-derived ACD plays in the effects of ethanol. Accordingly, in particular with respect to the motivational properties of ethanol, these studies were developed following two main strategies: on one hand, were aimed to challenge the suggestion that also ACD may exert motivational properties on its own, while, on the other, with the aid of enzymatic manipulations or ACD inactivation, were aimed to test the hypothesis that ethanol-derived ACD might have a role in ethanol motivational effects. Furthermore, recent evidence significantly contributed to highlight, as possible mechanisms of action of ACD, its ability to commit either dopaminergic and opioidergic transmission as well as to activate the Extracellular signal Regulated Kinase cascade transduction pathway in reward-related brain structures. In conclusion, and despite the observation that ACD seems also to have inherited the elusive nature of its parent compound, the behavioral and biochemical evidence reviewed points to ACD as a neuroactive molecule able, on its own and as ethanol metabolite, to exert motivational effects.

Keywords: acetaldehyde, behavior, ethanol, dopaminergic transmission, extracellular signal regulated kinase, opioidergic transmission, salsolinol

\section{INTRODUCTION}

Acetaldehyde (ACD) is well-known as a toxic compound and on this property was grounded the rationale for the use of disulfiram, an aldehyde dehydrogenase inhibitor, to treat alcoholism. However, toxicity does not necessarily involve perceived aversive effects and at the basis of this treatment are its aversive effects (nausea, headache, hot flushes, etc.) that discourage consumption. In spite of this, however, in the early 50's it was reported that some patients under treatment with the aldehyde dehydrogenase inhibitor (ALDH), antabuse, could experience pleasurable effects while ingesting small amounts of ethanol and it was postulated that ACD might have positive emotional as well as motivational effects (Chevens, 1953). After a long period of obsolescence from this observation, in the last decades the research on the role of ACD in the effects of ethanol, both as ethanol's metabolite and as chemical with its own motivational properties, has seen a renewed interest. To address this issue, the first approach has been to consider ethanol as a pro-drug of ACD. Indeed, the most radical view suggested that ACD could be responsible for all of the effects of ethanol and that alcoholism might, instead, be termed acetaldehydism (Raskin, 1975). Notably, a consistent body of evidence, suggesting that to exert its motivational properties ethanol must be metabolized into ACD, has been collected by different approaches including catalase manipulations (Aragon et al., 1985,
1991; Aragon and Amit, 1992), the use of alcohol dehydrogenase (ADH) (Amit, 1977; Brown et al., 1979; Smith et al., 1984; Quertemont and De Witte, 2001; Peana et al., 2008a) or ALDH inhibitors (Amit, 1977; Spivak et al., 1987a,b; Suh et al., 2006), the use of knock-out mice for the CYP2E1 isoform (Suh et al., 2006; Correa et al., 2009a) and the use of lentiviral vectors to silence the cell genome encoding for catalase or ADH synthesis (Karahanian et al., 2011). These approaches generated a large number of studies, summarized in comprehensive reviews (Quertemont et al., 2005; Correa et al., 2012), showing that locomotor (Escarabajal and Aragon, 2002; Martí-Prats et al., 2010; Ledesma and Aragon, 2012), anxiolytic (Correa et al., 2008; Escrig et al., 2012) and, in particular, motivational (Peana et al., 2008a,b, 2009, 2010a) properties of ethanol could be prevented by inhibiting either its peripheral and central metabolism or by ACD inactivation. Notably, two further issues, one related to the questioned ability of ACD to cross the blood brain barrier [see Correa et al. (2012) for an extensive discussion on this issue] and another related to the role of enhanced ethanol plasma concentrations that may in turn reach the brain, require to be dealt with while taking into consideration the consequences of blockade of ethanol peripheral metabolism.

Another approach to address the role of ACD in the motivational properties of ethanol has been to consider it as a chemical 
with neurobiological properties on its own. Indeed, also this line of investigation has generated a significant body of data that also converged toward the characterization of ACD as a neurochemical agent able to elicit locomotor activity (Correa et al., 2009b) and anxiolytic effects (Correa et al., 2008), to sustain drug discrimination (York, 1981; Redila et al., 2000, 2002; Quertemont and Grant, 2002), to affect cognition (Sershen et al., 2009), and to elicit motivational effects (York, 1981; Peana et al., 2008a, 2009, 2010b; Spina et al., 2010). Interestingly, the behavioral evidence for the characterization of ACD as a drug with motivational properties was gathered, from conditioned place preference (CPP) and self-administration studies, in parallel with electrophysiological, biochemical and immunohistochemical studies pointing also to the critical role of dopamine (DA) (Foddai et al., 2004; Melis et al., 2007; Enrico et al., 2009; Spina et al., 2010; Vinci et al., 2010; Sirca et al., 2011) and opioid (Pastor et al., 2004; Sánchez-Catalán et al., 2009; Peana et al., 2011) transmission as well as to the involvement of Extracellular signal Regulated Kinase (ERK) (Spina et al., 2010; Vinci et al., 2010) at the basis of ACD's motivational properties. The present review aims to recapitulate this evidence in support of the tenet of ACD as a molecule able to exert motivational effects in rodents (for a recent comprehensive review see Correa et al., 2012).

\section{CONDITIONED PLACE PREFERENCE AND SELF-ADMINISTRATION STUDIES}

The role of ACD in the positive motivational properties of ethanol has become an increasingly attractive matter of debate and many studies have attempted to establish whether ACD is necessary for the manifestation of the neurobiological and behavioral effects of ethanol. Such studies have been developed by the aid of compounds that increase as well as inhibit, both centrally and peripherally, the formation of ACD and by the aid of compounds able to sequester ACD into stable non-reactive adducts. ACD has been shown to elicit CPP after intracerebroventricular infusion (Smith et al., 1984) and after intragastric (Peana et al., 2008a) and intraperitoneal (Quertemont and De Witte, 2001) administration. Notably, under these conditions, ACD-elicited CPP shows a bell shaped dose-response curve similar to that of ethanol (Quertemont and De Witte, 2001; Peana et al., 2008a).

The isoforms of $\mathrm{ADH}$, normally found in gastric and hepatic tissue, represent the main metabolic pathway by which ethanol is converted into ACD upon ingestion (Baraona et al., 1991). Hence, provided that ethanol is not a substrate of brain $\mathrm{ADH}$ isoforms, the effect of the $\mathrm{ADH}$ competitive inhibitor, 4-methylpyrazole (4-MP), mostly used in behavioral studies is restricted to the peripheral metabolism of ethanol (Escarabajal and Aragon, 2002). In this paragraph we will focus our attention mostly on studies in which, to mimic the route commonly used by humans, ethanol and ACD were administered orally. In a CPP study, we showed that pretreatment with 4-MP reduces intragastric ethanol- $(1 \mathrm{~g} / \mathrm{kg})$ but not ACD- $(20 \mathrm{mg} / \mathrm{kg})$ induced CPP, suggesting that ACD, metabolically derived from ethanol, could be responsible for this effect (Peana et al., 2008a). As previously mentioned, however, the impact of these results is partly reduced by the observation that administration of 4-MP may also affect, indirectly, brain ACD (Spivak et al., 1987a,b).
In fact, when ethanol's metabolic conversion is prevented in the periphery it can reach the brain in greater amounts and can be metabolized therein by alternative pathways (catalase) (Aragon et al., 1985, 1991). This observation is also in agreement with the study by Tambour et al. (2007) reporting that the administration of cyanamide, a catalase and ALDH inhibitor, could prevent the locomotor stimulant effects of ethanol in mice and that this effect could be prevented by previous administration of 4-MP (Sanchis-Segura et al., 1999; Tambour et al., 2007).

Evidence of the role of ACD in the motivational properties of ethanol has also been provided by CPP experiments with Dpenicillamine, a compound, which acts by sequestering ACD into a non-reactive and stable adduct without altering ethanol metabolism (Nagasawa et al., 1978). Thus, peripheral administration of D-penicillamine, at doses devoid of motivational properties per se, prevents the acquisition of either ethanol- (Font et al., 2006a; Peana et al., 2008a) or ACD-induced CPP (Peana et al., 2008a). In addition, as in the case of the experiments with 4-MP, the specificity of pretreatment with D-penicillamine on ethanol-derived ACD was confirmed by its failure to affect morphine-elicited CPP. Further, indirect, evidence of the role of ACD in the motivational effects of ethanol comes from studies with L-cysteine, a thiol amino acid, also known for its ability to protect against ACD toxicity (Salaspuro, 2007). L-cysteine is a precursor of the antioxidant glutathione (Soghier and Brion, 2006) and binds ACD by way of cysteinylglycine, the first metabolite in glutathione breakdown (Kera et al., 1985). Notably, Lcysteine formulations have been developed to bind in the oral cavity ACD originating after heavy smoking and alcohol drinking (Salaspuro et al., 2002; Salaspuro, 2007). Such formulations offer a novel method for intervention studies aimed to fight the role of ACD in the pathogenesis of upper digestive tract cancer (Salaspuro, 2007), alcoholic cardiomyopathy, as well as against the chronic toxicity of ACD (Sprince et al., 1974). Accordingly, we found that L-cysteine reduces either ethanol- and ACDelicited CPP (Peana et al., 2009) supporting the notion that the generation and accumulation of ACD actively contributes to ethanol-induced CPP.

Several studies have found that ACD supports its selfadministration. This has been demonstrated in unselected rats self-administering ACD intravenously (Myers et al., 1982; Takayama and Uyeno, 1985), intracerebroventricularly (Brown et al., 1979) and into the VTA (McBride et al., 2002), the latter also in alcohol-preferring rats (Rodd-Henricks et al., 2002). Further evidence that ACD exerts positive motivational properties arises from the observation that rats also acquire and maintain oral ACD self-administration (Peana et al., 2010b; Cacace et al., 2012). Our work, in this regard, has been aimed to characterize the role that ethanol-derived ACD plays in the pharmacological properties of orally ingested ethanol. Thus, as in the CPP studies, we have found that inhibition of the metabolism of ethanol, by 4-MP, reduces oral ethanol self-administration behavior (Peana et al., 2008b) an effect that might also be attributed to an increased concentration of ethanol which falls on the right-hand side of its bell shaped dose response curve. On the other hand, we have recently demonstrated, for the first time that ACD shares with ethanol the ability to induce oral 
self-administration behavior further supporting the hypothesis that ACD itself exerts motivational effects (Peana et al., 2010b). Notably, rats self-administering ACD show extinction behavior when ACD is discontinued while gradually reinstate operant responses when ACD is reintroduced (Peana et al., 2010b). In addition, studies directed toward the characterization of the role of ACD, provided evidence that ethanol-derived ACD plays an important role in ethanol's motivational effects. Accordingly, previous findings have reported that intracerebroventricular the structural analogue of L-cysteine, D-penicillamine, reduces voluntary ethanol consumption in rats indicating that the central inactivation of ACD also blocks ethanol intake (Font et al., 2006b). On the other hand, L-cysteine reduces the acquisition and maintenance of oral ethanol self-administration as well as the reinstatement of ethanol-drinking and ethanol-seeking behaviors (Peana et al., 2010a, 2013a). Others studies examined the motivational effects of ACD under the break point that serves as an index of animals' motivation to work for the reinforcer. In these experiments $0.2 \% \mathrm{v} / \mathrm{v}$ ACD's break point was not statistically different from the break point of $10 \% \mathrm{v} / \mathrm{v}$ ethanol in spite of a 50 times lower concentration (Peana et al., 2012). On the other hand, ACD consumatory responses were paralleled by a relevant increase in ACD blood but not brain concentrations (Peana et al., 2010b). Furthermore, as in CPP and ethanol self-administration studies, during oral ACD selfadministration L-cysteine was shown to decrease acquisition, maintenance, deprivation effect as well as ACD break point without interfering with saccharin reinforcement (Peana et al., 2012).

The ability of L-cysteine to affect ethanol-induced motivation could reside in different mechanisms. The first is consistent with the conjugation/inactivation mechanism that would take place between ACD and the first metabolite of glutathione (Kera et al., 1985). Furthermore, being L-cysteine an analogue of L-glutamate (Thompson and Kilpatrick, 1996) it is posited to interact at presynaptic group I metabotropic glutamate receptors (mGluR) of the mGluR5 subtype to exert a positive modulatory control on synaptic glutamate release (Harman et al., 1984; Croucher et al., 2001). In support of these results is the finding that L-cysteine reduces ethanol-induced stimulation of DA transmission in the nucleus accumbens shell (Sirca et al., 2011). Finally, it is noteworthy in this regard that L-cysteine may cross the blood brain barrier through excitatory amino acid transporters (Chen and Swanson, 2003) thus leaving open the possibility that this compound might also act centrally.

The main system of central ethanol oxidation is mediated by the enzyme catalase (Aragon et al., 1991; Aragon and Amit, 1992; Zimatkin et al., 1998). By reacting with $\mathrm{H}_{2} \mathrm{O}_{2}$, brain catalase forms compound I (the catalase- $\mathrm{H}_{2} \mathrm{O}_{2}$ system), which is able to oxidize ethanol into ACD (Pastor et al., 2002; Ledesma and Aragon, 2012). Recently we showed that the $\mathrm{H}_{2} \mathrm{O}_{2}$ scavenging agent, alpha lipoic acid, dose-dependently reduces the maintenance and break point of oral ethanol self-administration under a progressive ratio schedule as well as the reinstatement of ethanol seeking behavior without suppressing saccharin selfadministration (Peana et al., 2013b). On a similar vein, a recent study by Ledesma and Aragon (2013) demonstrated that alpha lipoic acid reduces the acquisition and reconditioning of ethanolinduced CPP in mice. Overall, these data support the suggestion that a decrease in cerebral $\mathrm{H}_{2} \mathrm{O}_{2}$ availability, i.e., a reduced metabolic activity of brain catalase, by alpha lipoic acid administration may inhibit oral ethanol self-administration further suggesting that the brain catalase- $\mathrm{H}_{2} \mathrm{O}_{2}$ system, and therefore centrally formed ACD, plays a key role in the motivational effects of ethanol.

\section{ACETALDEHYDE, DOPAMINE, AND INTRACELLULAR SIGNALING}

The acute administration of ethanol elicits DA transmission in the rat nucleus accumbens (Imperato and Di Chiara, 1986; Howard et al., 2008) and this is also true in men whereby these increases in the ventral striatum positively correlate with the psychostimulant effect of ethanol (Boileau et al., 2003). Thus, a physiologically active DA transmission may represent the prerequisite for ethanol and, in accordance with Chevens (1953), also for ACD being able to elicit motivational effects. In this regard, in light of the hypothesized role of DA in the motivational effects of ACD, an indirect support comes from the clinical observation that subjects administered the DA biosynthesis inhibitor, alphamethyltyrosine, do not experience ethanol-induced stimulation and euphoria (Ahlenius et al., 1973). With these premises in mind this paragraph will present and discuss the preclinical studies that support the involvement of DA in the motivational effects of ACD.

The main line of experimental evidence of the involvement of DA in the effects of ACD was inspired by the known ability of ethanol to stimulate the firing rate of midbrain DA cells either in vivo (Gessa et al., 1985; Foddai et al., 2004) and in vitro (Brodie et al., 1990; Melis et al., 2007) as well as the release of DA from mesoaccumbens terminals (Imperato and Di Chiara, 1986; Howard et al., 2008). Indeed these data also inspired the experiments aimed to test whether ethanol-derived ACD, as well as ACD on its own, could stimulate the firing rate of DA neurons in the VTA (Foddai et al., 2004) and DA transmission in the nucleus accumbens (Ward et al., 1997; Melis et al., 2007; Enrico et al., 2009). Thus, in keeping with the well-established paradigm, successfully applied in behavioral (Peana et al., 2008a) and histochemical (Vinci et al., 2010) studies that envisioned the use of 4-MP to prevent ethanol peripheral metabolism, Foddai et al. (2004) showed that this ADH inhibitor prevents ethanol-elicited stimulation of firing rate of DA neurons in the VTA, demonstrating for the first time that metabolic conversion of ethanol into ACD plays a critical role in the ability of ethanol to activate mesencephalic DA cells (Foddai et al., 2004). This finding has been further extended by the study of Melis et al. (2007) in which, by recording VTA DA cells ex vivo, it was shown that ethanol and ACD similarly stimulate DA cells firing rate but also that the stimulatory effect of ethanol is prevented by inhibition of its metabolic conversion into ACD by the catalase inhibitor 3-aminotriazole (Melis et al., 2007).

Notably, all the above refers to the ability of ACD to affect DA cells function and transmission at the pre-synaptic level. Immunohistochemical data, however, have shown that the expression of phosphorylated Extracellular signal regulated 
kinase (pERK), taken as an index of post-synaptic DA-dependent neuronal activation (Acquas et al., 2007; Ibba et al., 2009), is similarly increased in the nucleus accumbens after the acute oral administration of either ethanol (Ibba et al., 2009; Vinci et al., 2010) and ACD (Vinci et al., 2010). In addition, ethanolelicited increase of pERK expression in the nucleus accumbens could be prevented either by 4-MP and D-penicillamine (Vinci et al., 2010). ERK phosphorylation may take place by a number of factors ranging from extracellular signals to increased intracellular $\mathrm{Ca}^{++}$concentrations via the sequential activation of a kinase cascade (Sweatt, 2004). This activated kinase has been related to neuronal plasticity (Fasano and Brambilla, 2011) and to long-term behavioral events that may be triggered by addictive drugs (Valjent et al., 2004; Girault et al., 2007) such as acquisition of conditioned responses (Beninger and Gerdjikov, 2004) as well as reinstatement of ethanol seeking (Radwanska et al., 2008; Schroeder et al., 2008; Peana et al., 2013a) in selfadministration experiments. Accordingly, we found that while acute ACD administration elicits pERK in the nucleus accumbens (and other nuclei of the extended amygdala) (Vinci et al., 2010), the intracerebroventricular administration of PD98059, an inhibitor of the mitogen-activating extracellular kinase (MEK), the kinase responsible of ERK phosphorylation, prevents the acquisition of ACD-elicited CPP (Spina et al., 2010). In addition, the involvement of DA in these studies is supported by the experiments with the DA $\mathrm{D}_{1}$ antagonist SCH 39166 (Ibba et al., 2009; Spina et al., 2010; Vinci et al., 2010). In fact, we demonstrated that either oral ethanol- (Ibba et al., 2009) and ACD- (Vinci et al., 2010) elicited nucleus accumbens increases of pERK expression and ACD-elicited CPP (Spina et al., 2010) could be prevented by blockade of $D_{1}$ receptors by SCH 39166.

A further line of experimental evidence, though yet speculative, of the involvement of DA in the effects of ACD originates from the studies on the condensation product(s) of ACD which, in particular when condensates with DA, can either spontaneously and enzymatically (Chen et al., 2011) generate 1methyl-6,7-dihydroxy-1,2,3,4-tetrahydroisoquinoline (salsolinol) (Yamanaka et al., 1970; Jamal et al., 2003). Interestingly, since its discovery, this molecule has been related to ethanol (Davis and Walsh, 1970; Davis et al., 1970) and it was hypothesized that at least the DA-mediated effects of ethanol could be attributed to salsolinol (Davis and Walsh, 1970; Davis et al., 1970). This compound, indeed, has recently been reported to stimulate in vitro DA cells firing rate in the posterior VTA (Xie and Ye, 2012; Xie et al., 2012) and also, when applied into the VTA in vivo, to elicit DA transmission in the rat nucleus accumbens (Rodd et al., 2003; Deehan et al., 2012) and sustain its self-administration (Rodd et al., 2008). Thus, these data seem to collectively point to salsolinol as a substance that may exert motivational effects by virtue of its ability to involve mesolimbic DA. However, the relationship between ACD, DA and salsolinol still awaits to be fully disclosed.

\section{ACETALDEHYDE AND OPIOIDS}

Acute administration of ethanol increases endogenous opioid (endorphin and enkephalin) release from brain slices, pituitary gland and increases blood levels of opioids in humans in vivo (see Herz, 1997 for a comprehensive review). Acute alcohol administration also enhances gene expression of both endorphin and enkephalin in selected brain areas of rats, whereas chronic ethanol administration reduces gene expression, making less of opioid peptides available for release (Herz, 1997). Since opioid transmission, in both the VTA and nucleus accumbens, regulates the release of DA from mesolimbic neurons, ethanol-induced opioid release may produce reinforcement by modulating DA transmission. Accordingly, opioid antagonists decrease the motivational properties of ethanol in rats self-administering ethanol by interfering with ethanol-dependent dopaminergic activation (Acquas et al., 1993; Benjamin et al., 1993; Di Chiara et al., 1996; Gonzales and Weiss, 1998) as the motivational effects of ethanol by opioid antagonists may involve an opioid-DA link (Di Chiara et al., 1996). However, another line of evidence for the involvement of the endogenous opioid system in the motivational effects of ethanol appears to be related to its first metabolite, ACD. In fact, there are several proofs to support that opioids are implicated in the motivational effects of ACD as well. The first arises from the early observation by Myers et al. (1984) demonstrating that naloxone decreases intravenous ACD self-administration. The second arises from the observation that naltrexone reduces oral ACD selfadministration (Peana et al., 2011). In particular, we observed that this effect could be mediated by an involvement of $\mu_{1}$ opioid receptors since naloxonazine, a $\mu_{1}$ selective opioid receptor antagonist, reduced the maintenance phase of ACD self-administration (Peana et al., 2011). The mechanism by which opioid antagonists affect the motivational properties of ACD is unclear. In this regard one might consider that ACD on its own, and as a consequence of the metabolism of ethanol, activates neuronal firing of DA cells in the VTA (Foddai et al., 2004), stimulates DA transmission (Melis et al., 2007; Enrico et al., 2009; Sirca et al., 2011) and ERK phosphorylation in the nucleus accumbens (Vinci et al., 2010). This possibility appears in agreement with the observation that blockade of $\mu$ opioid receptors also prevents ERK phosphorylation in the nucleus accumbens (Peana et al., 2011). An alternative possibility, yet to be fully demonstrated, is offered by the suggestion that the condensation product between ACD and DA, salsolinol (see above), acts via stimulation of $\mu$ opioid receptors (Hipolito et al., 2009, 2010, 2012; Xie et al., 2012).

\section{DISCUSSION AND CONCLUSIONS}

The reviewed literature indicates that ACD has its own motivational properties as assessed by CPP and self-administration studies (Peana et al., 2008a, 2010b; Spina et al., 2010) and also that this property is grounded on its ability to involve mesolimbic DA (Foddai et al., 2004; Melis et al., 2007; Spina et al., 2010; Vinci et al., 2010), $\mu$ opioid receptors -mediated transmission (Peana et al., 2011) as well as phosphorylated ERK in the nucleus accumbens (Spina et al., 2010; Vinci et al., 2010; Peana et al., 2011). In addition, a wealth of experimental evidence supports that the motivational effects of ethanol are mediated by its metabolism into ACD either in the periphery or in the brain. Accordingly, this has been demonstrated by inhibiting the production of ACD in the periphery (inhibition of $\mathrm{ADH}$ ), by inhibiting the generation of brain ACD (inhibition of brain catalase) or by reducing 
ACD bioavailability (Font et al., 2006a,b; Peana et al., 2008a, 2009, 2010a, 2013a,b; Enrico et al., 2009; Sirca et al., 2011; Correa et al., 2012). All these observations support the tenet that the generation of central and peripheral, but not peripherally accumulated

\section{REFERENCES}

Acquas, E., Meloni, M., and Di Chiara, G. (1993). Blockade of delta-opioid receptors in the nucleus accumbens prevents ethanol-induced stimulation of dopamine release. Eur. J. Pharmacol. 230, 239-241. doi: 10.1016/0014-2999(93)90809-V

Acquas, E., Pisanu, A., Spiga, S., Plumitallo, A., Zernig, G., and Di Chiara, G. (2007). Differential effects of intravenous R,S- $( \pm)-3,4$ methylenedioxymethamphetamine (MDMA, ecstasy) and its S(+)- and $\mathrm{R}(-)$-enantiomers on dopamine transmission and extracellular signal regulated kinase phosphorylation (pERK) in the rat nucleus accumbens shell and core. J. Neurochem. 102, 121-132. doi: 10.1111/j.1471-4159.2007.04451.x

Ahlenius, S., Carlsson, A., Engel, J., Svensson, T., and Södersten, P. (1973). Antagonism by alpha methyltyrosine of the ethanolinduced stimulation and euphoria in man. Clin. Pharmacol. Ther. 14, 586-591.

Amit, Z. (1977). Brain and liver aldehyde dehydrogenase: relations to ethanol consumption in wistar rats. Neuropharmacology 16, 781-784. doi: 10.1016/0028-3908 (77) $90137-X$

Aragon, C. M., and Amit, Z. (1992). The effect of 3-amino-1,2,4-triazole on voluntary ethanol consumption: evidence for brain catalase involvement in the mechanism of action. Neuropharmacology 31, 709-712. doi: 10.1016/0028-3908 (92)90150-N

Aragon, C. M., Sternklar, G., and Amit, Z. (1985). A correlation between voluntary ethanol consumption and brain catalase activity in the rat. Alcohol 2, 353-356. doi: 10.1016/0741-8329 (85)90074-6

Aragon, C. M., Stotland, L. M., and Amit, Z. (1991). Studies on ethanol-brain catalase interaction: evidence for central ethanol oxidation. Alcohol. Clin. Exp. Res. 15, 165-169. doi: 10.1111/j.15300277.1991.tb01848.x

Baraona, E., Yokoyama, A., Ishii, H., Hernandez-Munoz, R., Takagi, T., Tsuchiya, M., et al. (1991). Lack of alcohol dehydrogenase isoenzyme activities in the stomach of Japanese subjects. Life Sci. 49,
1929-1934. doi: 10.1016/00243205(91)90295-M

Beninger, R. J., and Gerdjikov, T. (2004). The role of signaling molecules in reward-related incentive learning. Neurotox. Res. 61, 91-104. doi: 10.1007/BF03033301

Benjamin, D., Grant, E. R., and Pohorecky, L. A. (1993). Naltrexone reverses ethanol-induced dopamine release in the nucleus accumbens in awake, freely moving rats. Brain Res. 621,137-140. doi: 10.1016/0006-8993(93)90309-B

Boileau, I., Assaad, J. M., Pihl, R. O., Benkelfat, C., Leyton, M., Diksic, M., et al. (2003). Alcohol promotes dopamine release in the human nucleus accumbens. Synapse 49, 226-231. doi: 10.1002/syn.10226

Brodie, M. S., Shefner, S. A., and Dunwiddie, T. V. (1990). Ethanol increases the firing rate of dopamine neurons of the rat ventral tegmental area in vitro. Brain Res. 508, 65-69. doi: 10.1016/0006-8993 (90)91118-Z

Brown, Z. W., Amit, Z., and Rockman, G. E. (1979). Intraventricular selfadministration of acetaldehyde, but not ethanol, in naïve laboratory rats. Psychopharmacology (Berl.) 64, 271-276. doi: 10.1007/BF00427509

Cacace, S., Plescia, F., Barberi, I., and Cannizzaro, C. (2012). Acetaldehyde oral selfadministration: evidence from the operant-conflict paradigm. Alcohol. Clin. Exp. Res. 36, 1278-1287. doi: 10.1111/j.1530-0277.2011.01725.x

Chen, A., Arshad, A., Qing, H., Wang, R., Lu, J., and Deng, Y. (2011). Enzymatic condensation of dopamine and acetaldehyde: a salsolinol synthase from rat brain. Biologia 66, 1183-1188. doi: 10.2478/s11756-011-0134-y

Chen, Y., and Swanson, R. A. (2003). The glutamate transporters EAAT2 and EAAT3 mediate cysteine uptake in cortical neuron cultures. J. Neurochem. 84, 1332-1339. doi: 10.1046/j.1471-4159.2003.01630.x

Chevens, L. C. F. (1953). Antabuse addiction. Br. J. Med. 1, 1450-1451. doi: 10.1136/bmj.1.4825.1450-c

Correa, M., Manrique, H. M., Font, L., Escrig, M. A., and Aragon, C. M. (2008). Reduction in the anxiolytic effects of ethanol by centrally formed acetaldehyde: the role of catalase inhibitors and

(Escrig et al., 2012), ACD actively participates in the positive motivational properties of ethanol and raise the possibility that its role can be exploited to devise novel pharmacological approaches that target alcohol abuse related problems.

acetaldehyde-sequestering agents. Psychopharmacology 200, 455-464. doi: 10.1007/s00213-008-1219-3

Correa, M., Salamone, J. D., Segovia, K. N., Pardo, M., Longoni, R., Spina, L., et al. (2012). Piecing together the puzzle of acetaldehyde as a neuroactive agent. Neurosci. Biobehav. Rev. 36, 404-430. doi: 10.1016/j.neubiorev.2011.07.009

Correa, M., Viaggi, C., Escrig, M. A., Pascual, M., Guerri, C., Vaglini, F. et al. (2009a). Ethanol intake and ethanol-induced locomotion and locomotor sensitization in Cyp2e1 knockout mice. Pharmacogenet. Genomics 19, 217-225. doi: 10.1097/FPC.0b013e328324e726

Correa, M., Arizzi-Lafrance, M. N. and Salamone, J. D. (2009b). Infusions of acetaldehyde into the arcuate nucleus of the hypothalamus induce motor activity in rats. Life Sci. 84, 321-327. doi: 10.1016/j.lfs.2008.12.013

Croucher, M. J., Thomas, L. S., Ahmadi, H., Lawrence, V., and Harris, J. R. (2001). Endogenous sulphur-containing amino acids: potent agonists at presynaptic metabotropic glutamate autoreceptors in the rat central nervous system. $B r . \quad J$. Pharmacol. 133, 815-824. doi: 10.1038/sj.bjp.0704138

Davis, V. E., and Walsh, M. J. (1970). Alcohol, amines, and alkaloids: a possible biochemical basis for alcohol addiction. Science 167, 1005-1007. doi: 10.1126/science.167.3920.1005

Davis, V. E., Walsh, M. J., and Yamanaka, Y. (1970). Augmentation of alkaloid formation from dopamine by alcohol and acetaldehyde in vitro. J. Pharmacol. Exp. Ther. 174, 401-412.

Deehan, G. A. Jr., Engleman, E. A. Ding, Z. M., McBride, W. J., and Rodd, Z. A. (2012). Microinjections of acetaldehyde or salsolinol into the posterior ventral tegmental area increase dopamine release in the nucleus accumbens shell. Alcohol. Clin. Exp. Res. 37, 722-729. doi: 10.1111/acer.12034

Di Chiara, G., Acquas, E., and Tanda, G. (1996). Ethanol as a neurochemical surrogate of conventional reinforcers: the dopamine-opioid link. Alcohol 13, 13-17. doi: 10.1016/0741-8329(95)02034-9
Enrico, P., Sirca, D., Mereu, M., Peana, A. T., Lintas, A., Golosio, A., et al. (2009). Acetaldehyde sequestering prevents ethanolinduced stimulation of mesolimbic dopamine transmission. Drug Alcohol Depend. 100, 265-271. doi: 10.1016/j.drugalcdep.2008.10.010

Escarabajal, M. D., and Aragon, C. M. (2002). The effect of cyanamide and 4-methylpyrazole on the ethanol-induced locomotor activity in mice. Pharmacol. Biochem. Behav. 72, 389-395. doi: 10.1016/S0091-3057(01)00762-6

Escrig, M. A., Pardo, M., Aragon, C. M., and Correa, M. (2012) Anxiogenic and stress-inducing effects of peripherally administered acetaldehyde in mice: similarities with the disulfiramethanol reaction. Pharmacol. Biochem. Behav. 100, 404-412. doi: 10.1016/j.pbb.2011.10.002

Fasano, S., and Brambilla, R. (2011). Ras-ERK signaling in behavior: old questions and new perspectives. Front. Behav. Neurosci. 5:79. doi: 10.3389/fnbeh.2011.00079

Foddai, M., Dosia, G., Spiga, S., and Diana, M. (2004). Acetaldehyde increases dopaminergic neuronal activity in the VTA. Neuropsychopharmacology 29, 530-536. doi: 10.1038/sj.npp. 1300326

Font, L., Aragon, C. M., and Miquel, M. (2006a). Ethanol-induced conditioned place preference, but not aversion, is blocked by treatment with D-penicillamine, an inactivation agent for acetaldehyde. Psychopharmacology 184, 56-64. doi: 10.1007/s00213-005-0224-z

Font, L., Aragon, C. M., and Miquel, M. (2006b). Voluntary ethanol consumption decreases after the inactivation of central acetaldehyde by d-penicillamine. Behav. Brain Res. 171, 78-86. doi: 10.1016/j.bbr.2006.03.020

Gessa, G. L., Muntoni, F., Vargiu, L., and Mereu, G. (1985). Low doses of ethanol activate dopaminergic neurons in the ventral tegmental area. Brain Res. 348, 201-203. doi: 10.1016/0006-8993 (85)90381-6

Girault, J. A., Valjent, E., Caboche, J., and Herve, D. (2007). ERK2: a logical AND gate critical for drug-induced plasticity? Curr. 
Opin. Pharmacol. 7, 77-85. doi: 10.1016/j.coph.2006.08.012

Gonzales, R. A., and Weiss, F. (1998). Suppression of ethanol-reinforced behavior by naltrexone is associated with attenuation of the ethanol-induced increase in dialysate dopamine levels in the nucleus accumbens. J. Neurosci. 18, 10663-10671.

Harman, L. S., Mottley, C., and Mason, R. P. (1984). Free radical metabolites of L-cysteine oxidation. J. Biol. Chem. 259, 5606-5611.

Herz, A. (1997). Endogenous opioid systems and alcohol addiction. Psychopharmacology 129, 99-111. doi: 10.1007/s002130050169

Hipolito, L., Sánchez-Catalán, M. J., Granero, L., and Polache, A. (2010). Locomotor stimulant effects of acute and repeated intrategmental injections of salsolinol in rats: role of mu-opioid receptors. Psychopharmacology 209, 1-11. doi: 10.1007/s00213-009-1751-9

Hipolito, L., Sánchez-Catalán, M. J., Martí-Prats, L., Granero, L., and Polache, A. (2012). Revisiting the controversial role of salsolinol in the neurobiological effects of ethanol: old and new vistas. Neurosci. Biobehav. Rev. 36, 362-378. doi: 10.1016/j.neubiorev.2011.07.007

Hipolito, L., Sánchez-Catalán, M. J., Zornoza, T., Polache, A., and Granero, L. (2009). Local salsolinol modulates dopamine extracellular levelsfrom rat nucleus accumbens: shell/core differences. Neurochem. Int. 55, 187-192. doi: 10.1016/j.neuint.2009.02.014

Howard, E. C., Schier, C. J., Wetzel, J. S., Duvauchelle, C. L., and Gonzales, R. A. (2008). The shell of the nucleus accumbens has a higher dopamine response compared with the core after non-contingent intravenous ethanol administration. Neuroscience 154, 1042-1053. doi: 10.1016/j.neuroscience.2008.04.014

Ibba, F., Vinci, S., Spiga, S., Peana, A. T., Assaretti, A. R., Spina, L., et al. (2009). Ethanol-induced extracellular signal regulated kinase: role of dopamine D1 receptors. Alcohol. Clin. Exp. Res. 33, 858-867. doi: 10.1111/j.1530-0277.2009.00907.x

Imperato, A., and Di Chiara, G. (1986). Preferential stimulation of dopamine release in the nucleus accumbens of freely moving rats by ethanol. J. Pharmacol. Exp. Ther. 239, 219-228.

Jamal, M., Ameno, K., Ameno, S., Okada, N., and Ijiri, I. (2003). In vivo study of salsolinol produced by a high concentration of acetaldehyde in the striatum and nucleus accumbens of free-moving rats. Alcohol. Clin. Exp. Res. 27(8 Suppl.), 79S-84S. doi: 10.1097/01. ALC.0000078617.33026.AD

Karahanian, E., Quintanilla, M. E., Tampier, L., Rivera-Meza, M., Bustamante, D., Gonzalez-Lira, V., et al. (2011). Ethanol as a prodrug: brain metabolism of ethanol mediates its motivationaleffects. Alcohol. Clin. Exp. Res. 35, 606-612. doi: 10.1111/j.1530-0277.2011.01439.x

Kera, Y., Kiriyama, T., and Komura, S. (1985). Conjugation of acetaldehyde with cysteiniylglycine, the first metabolite in glutathione breakdown by c-glutamyltranspeptidase. Agents Actions 17, 48-52. doi: 10.1007/BF01966681

Ledesma, J. C., and Aragon, C. M. (2013). Acquisition and reconditioning of ethanol-induced conditioned place preference in mice is blocked by the $\mathrm{H}_{2} \mathrm{O}_{2}$ scavenger alpha lipoic acid. Psychopharmacology 226, 673-685. doi: 10.1007/s00213-012-2831-9

Ledesma, J. C., and Aragon, C. M. G. (2012). Alpha lipoic acid, a scavenging agent for $\mathrm{H}_{2} \mathrm{O}_{2}$, reduces ethanolstimulated locomotion in mice. Psychopharmacology 219, 171-180. doi: 10.1007/s00213-011-2407-0

Martí-Prats, L., Sánchez-Catalán, M. J., Hipólito, L., Orrico, A., Zornoza, T., Polache, A., et al. (2010). Systemic administration of D-penicillamine prevents the locomotor activation after intraVTA ethanol administration in rats. Neurosci. Lett. 483, 143-147. doi: 10.1016/j.neulet.2010.07.081

McBride, W. J., Li, T. K., Deitrich, R. A., Zimatkin, S., Smith, B. R., and Rodd-Henricks, Z. A. (2002). Involvement of acetaldehyde in alcohol addiction. Alcohol. Clin. Exp. Res. 26, 114-119. doi: 10.1111/j.15300277.2002.tb02439.x

Melis, M., Enrico, P., Peana, A. T., and Diana, M. (2007). Acetaldehyde mediates alcohol activation of the mesolimbic dopamine system. Eur. J. Neurosci. 26, 2824-2833. doi: 10.1111/j.1460-9568.2007.05887.x

Myers, W. D., Ng, K. T., and Singer, G. (1982). Intravenous self-administration of acetaldehyde in the rat as a function of schedule, food deprivation and photoperiod. Pharmacol. Biochem. Behav. 17, 807-811. doi: 10.1016/0091-3057(82)90364-1

Myers, W. D., Ng, K. T., and Singer, G. (1984). Effects of naloxone and buprenorphine on intravenous acetaldehyde self-injection in rats.
Physiol. Behav. 33, 449-455. doi: 10.1016/0031-9384(84)90168-9

Nagasawa, H. T., Goon, D. J., and DeMaster, E. G. (1978). 2,5,5Trimethylthiazolidine-4-carboxylic acid, a D(-)-penicillamine-directed pseudometabolite of ethanol. Detoxication mechanism for acetaldehyde. J. Med. Chem. 21, 1274-1279. doi: 10.1021/jm00210 a019

Pastor, R., Sanchis-Segura, C., and Aragon, C. M. (2002). Ethanolstimulated behaviour in mice is modulated by brain catalase activity and $\mathrm{H}_{2} \mathrm{O}_{2}$ rate of production. Psychopharmacology 165, 51-59. doi: 10.1007/s00213-0021241-9

Pastor, R., Sanchis-Segura, C., and Aragon, C. M. (2004). Brain catalase activity inhibition as well as opioid receptor antagonism increases ethanol-induced HPA axis activation. Alcohol. Clin. Exp. Res. 28, 1898-1906. doi: 10.1097/01.ALC. 0000148107.64739 .76

Peana, A. T., Assaretti, A. R., Muggironi, G., Enrico, P., and Diana, M. (2009). Reduction of ethanol-derived acetaldehyde induced motivational properties by L-cysteine. Alcohol. Clin. Exp. Res. 33, 43-48. doi: 10.1111/j.1530-0277.2008.00809.x

Peana, A. T., Enrico, P., Assaretti, A. R., Pulighe, E., Muggironi, G., Nieddu, M., et al. (2008a). Key role of ethanol-derived acetaldehyde in the motivational properties induced by intragastric ethanol: a conditioned place preference study in the rat. Alcohol. Clin. Exp. Res. 32, 249-258. doi: 10.1111/j.15300277.2007.00574.X

Peana, A. T., Assaretti, A. R., Muggironi, G., Enrico, P., and Diana, M. (2008b). "The peripheral competitive inhibitor of alcohol dehydrogenase, 4methylpyrazole, reduces oral ethanol self-administration," in ESBRA2008 Nordmann Award Meeting-Animal Models in Alcohol Research, (Cagliari), 26-27.

Peana, A. T., Giugliano, V., Rosas, M., Sabariego, M., and Acquas, E. (2013a). Effects of L-cysteine on reinstatement of ethanol seeking behavior and on reinstatementelicited ERK phosphorylation in the rat nucleus accumbens shell. Alcohol. Clin. Exp. Res. 37(Suppl. 1), E329-E337. doi: 10.1111/j.15300277.2012.01877.x

Peana, A. T., Muggironi, G., Fois, G., and Diana, M. (2013b). Alphalipoic acid reduces ethanol selfadministration in rats. Alcohol. Clin.
Exp. Res. doi: 10.1111/acer.12169. [Epub ahead of print].

Peana, A. T., Muggironi, G., Calvisi, G., Enrico, P., Mereu, M., Nieddu, M., et al. (2010a). L-cysteine reduces oral ethanol self-administration and reinstatement of ethanol-drinking behavior in rats. Pharmacol. Biochem. Behav. 94, 431-437. doi: 10.1016/j.pbb.2009.10.005

Peana, A. T., Muggironi, G., and Diana, M. (2010b). Acetaldehydemotivationaleffects; a study on oral self-administration behavior. Front. Psychiatry 1:23. doi: 10.3389/fpsyt.2010.00023

Peana, A. T., Muggironi, G., Fois, G. R., Zinellu, M., Sirca, D., and Diana, M. (2012). Effect of (L)-cysteine on acetaldehyde self-administration. Alcohol 46, 489-497. doi: 10.1016/j.alcohol.2011.10.004

Peana, A. T., Muggironi, G., Fois, G. R., Zinellu, M., Vinci, S., and Acquas, E. (2011). Effect of opioid receptor blockade on acetaldehyde self-administration and ERK phosphorylation in the rat nucleus accumbens. Alcohol 45, 773-783. doi: 10.1016/j.alcohol.2011.06.003

Quertemont, E., and De Witte, P. (2001). Conditioned stimulus preference after acetaldehyde but not ethanol injections. Pharmacol. Biochem. Behav. 68, 449-454. doi: 10.1016/S0091-3057(00)00486-X

Quertemont, E., and Grant, K. A. (2002). Role of acetaldehyde in the discriminative stimulus effects of ethanol. Alcohol. Clin. Exp. Res. 26, 812-817. doi: 10.1111/j.15300277.2002.tb02609.x

Quertemont, E., Tambour, S., and Tirelli, E. (2005). The role of acetaldehyde in the neurobehavioral effects of ethanol: a comprensive review of animal studies. Prog. Neurobiol. 75, 247-274. doi: 10.1016/j.pneurobio. 2005.03.003

Radwanska, K., Wrobel, E., Korkosz, A., Rogowski, A., Kostowski, W., Bienkowski, P., et al. (2008). Alcohol relapse induced by discrete cues activates components of AP-1 transcription factor and ERK pathway in the rat basolateral and central amygdala. Neuropsychopharmacology 33, 1835-1846. doi: 10.1038/sj.npp. 1301567

Raskin, N. H., (1975). Editorial: alcoholism or acetaldehydism? N. Engl. J. Med. 292, 422-423. doi 10.1056/NEJM197502202920811

Redila, V. A., Aliatas, E., Smith, B. R., and Amit, Z. (2002). Effects of ethanol on an acetaldehyde drug discrimination with a conditioned taste aversion procedure. Alcoho 
28, 103-109. doi: 10.1016/S07418329(02)00270-7

Redila, V. A., Smith, B. R., and Amit, Z. (2000). The effects of aminotriazole and acetaldehyde on an ethanol drug discrimination with a conditioned taste aversion procedure. Alcohol 21, 279-285. doi: 10.1016/S0741-8329 (00)00096-3

Rodd, Z. A., Bell, R. L., Zhang, Y., Goldstein, A., Zaffaroni, A., McBride, W. J., et al. (2003). Salsolinol produces motivational effects in the nucleus accumbens shell of alcohol-preferring $(\mathrm{P})$ rats. Alcohol. Clin. Exp. Res. 27, 440-449. doi: 10.1097/01.ALC.0000056612. 89957.B4

Rodd, Z. A., Oster, S. M., Ding, Z. M., Toalston, J. E., Deehan, G., Bell, R. L., et al. (2008). The motivational properties of salsolinol in the ventral tegmental area: evidence for regional heterogeneity and the involvement of serotonin and dopamine. Alcohol. Clin. Exp. Res. 32, 230-239. doi: 10.1111/j.1530-0277.2007.00572.x

Rodd-Henricks, Z. A., Melendez, R. I., Zaffaroni, A., Goldstein, A., McBride, W. J., and Lu, T. K. (2002). The motivationaleffects of acetaldehyde in the posterior ventral tegmental area of alcohol-preferring rats. Pharmacol. Biochem. Behav. 72, 55-64. doi: 10.1016/S0091-3057(01)00733-X

Salaspuro, V. (2007). Pharmacological treatments and stategies for reducing oral and intestinal acetaldehyde. Novartis Found. Symp. 285, 145-153. doi: 10.1002/9780470511848.ch11

Salaspuro, V., Hietala, J., Kaihovaara, P., Pihlajarinne, L., Marvola, M., and Salaspuro, M. (2002). Removal of acetaldehyde from saliva by a slowrelease buccal tablet of L-cysteine. Int. J. Cancer 97, 361-364. doi: 10.1002/ijc. 1620

Sánchez-Catalán, M. J., Hipólito, L., Zornoza, T., Polache, A., and Granero, L. (2009). Motor stimulant effects of ethanol and acetaldehyde injected into the posterior ventral tegmental area of rats: role of opioid receptors. Psychopharmacology 204, 641-653. doi: 10.1007/s00213-0091495-6

Sanchis-Segura, C., Miquel, M., Correa, M., and Aragon, C. M. (1999). Daily injections of cyanamide enhance both ethanol-induced locomotion and brain catalase activity. Behav. Pharmacol. 10, 459-465. doi: 10.1097/00008877-19990900000004

Schroeder, J. P., Spanos, M., Stevenson, J. R., Besheer, J., Salling, M., and Hodge, C. W. (2008). Cue-induced reinstatement of alcohol-seeking behavior is associated with increased $\operatorname{ERK}(1 / 2)$ phosphorylation in specific limbic brain regions: blockade by the mGluR5 antagonist MPEP. Neuropharmacology 55, 546-554. doi: $\quad 10.1016 /$ j.neuropharm.2008 06.057

Sershen, H., Shearman, E., Fallon, S., Chakraborty, G., Smiley, J., and Lajtha, A. (2009). The effects of acetaldehyde on nicotineinduced transmitter levels in young and adult brain areas. Brain Res. Bull. 79, 458-462. doi: 10.1016/j.brain resbull.2009.04.005

Sirca, D., Enrico, P., Mereu, M., Peana, A. T., and Diana, M. (2011). L-cysteine prevents ethanol-induced stimulation of mesolimbic dopamine transmission. Alcohol. Clin. Exp. Res. 35, 862-869. doi: 10.1111/j.1530-0277. 2010.01416.x

Smith, B. R., Amit, Z., and Splawinsky, J. (1984). Conditioned place preference induced by intraventricular infusions of acetaldehyde. Alcohol 1, 193-195. doi: 10.1016/0741-8329 (84) $90097-1$

Soghier, L. M., and Brion, L. P. (2006) Cysteine, cystine or $\mathrm{N}$-acetylcysteine supplementation in parenterally fed neonated. Cochrane Database Syst. Rev. 18:CD004869. doi: 10.1002/14651858.CD004869.pub2

Spina, L., Longoni, R., Vinci, S., Ibba, F., Peana, A. T., Muggironi, G., et al. (2010). Role of dopamine D1 receptors and extracellular signal regulated kinase in the motivational properties of acetaldehyde as assessed by place preference conditioning. Alcohol. Clin. Exp. Res. 34, 607-616. doi: 10.1111/j.15300277.2009.01129.x

Spivak, K., Aragon, C. M., and Amit, Z. (1987a). Alterations in brain aldehyde dehydrogenase activity modify ethanol-induced conditioned taste aversion. Alcohol. Clin. Exp. Res. 11, 513-517. doi: 10.1111/j.15300277.1987.tb00163.x
Spivak, K., Aragon, C. M., and Amit, Z. (1987b). Alterations in brain aldehyde dehydrogenase activity modify the locomotor effects produced by ethanol in rats. Alcohol Drug Res. 7 , 481-491.

Sprince, H., Parker, C. M., Smith, G. G., and Gonzales, L. J. (1974) Protection against acetaldehyde toxicity in the rat by L-cysteine, thiamin and L-2-methylthiazolidine4-carboxylic acid. Agents Actions 4 125-130. doi: 10.1007/BF01966822

Suh, J. J., Pettinati, H. M., Kampman, K. M., and O'Brien, C. P. (2006). The status of disulfiram: a half of a century later. J. Clin. Psychopharmacol. 26, 290-302. doi: $\quad 10.1097 / 01 . j c p .0000222512$ 25649.08

Sweatt, J. D. (2004). Mitogen-activated protein kinases in synaptic plasticity and memory. Curr. Opin. Neurobiol. 14, 311-317. doi 10.1016/j.conb.2004.04.001

Takayama, S., and Uyeno, E. T. (1985). Intravenous self-administration of ethanol and acetaldehyde by rats. Yakubutsu Seishin Kodo 5, 329-334.

Tambour, S., Closon, C., Tirelli, E. and Quertemont, E. (2007). Effects of cyanamide and acetaldehyde accumulation on the locomotor stimulant and sedative effects of ethanol in mice. Behav. Pharmacol. 18, 777-784. doi 10.1097/FBP.0b013e3282f158ca

Thompson, G. A., and Kilpatrick, I. C. (1996). The neurotransmitter candidature of sulphur-containing excitatory amino acids in the mammalian central nervous system. Pharmacol. Ther. 72, 25-36. doi 10.1016/S0163-7258(96)00097-6

Valjent, E., Pages, C., Herve, D., Girault, J. A., and Caboche, J. (2004) Addictive and non-addictive drugs induce distinct and specific patterns of ERK activation in mouse brain Eur. J. Neurosci. 19, 1826-1836. doi 10.1111/j.1460-9568.2004.03278.x

Vinci, S., Ibba, F., Longoni, R., Spina L., Spiga, S., and Acquas, E. (2010). Acetaldehyde elicits ERK phosphorylation in the rat nucleus accumbens and extended amygdala. Synapse 64, 916-927. doi: $10.1002 /$ syn. 20811

Ward, R. J., Colantuoni, C., Dahchour A., Quertemont, E., and De Witte, P. (1997). Acetaldehyde-induced changes in monoamine and amino acid extracellular microdialysate content of the nucleus accumbens. Neuropharmacology 36, 225-232. doi: 10.1016/S0028-3908 (97)00007-5

Xie, G., Hipólito, L., Zuo, W., Polache, A., Granero, A., Krnjevic, K. et al. (2012). Salsolinol stimulates dopamine neurons in slices of posterior ventral tegmental area indirectly by activating $\mu$ opioid receptors. J. Pharmacol. Exp. Ther. 341, 43-50. doi: 10.1124/jpet.111.186833

Xie, G., and Ye, J. H. (2012). Salsolinol facilitates glutamatergic transmission to dopamine neurons in the posterior ventral tegmental area of rats. PLoS ONE 7:e36716. doi: 10.1371/journal.pone.0036716

Yamanaka, Y., Walsh, M. J., and Davis, V. E. (1970). Salsolinol, an alkaloid derivative of dopamine formed in vitro during alcohol metabolism. Nature 227, 1143-1144. doi: 10.1038/2271143a0

York, J. L. (1981). The ethanol stimulus in rats with differing ethanol preferences. Psychopharmacology 74 339-343. doi: 10.1007/BF00432743

Zimatkin, S. M., Liopo, A. V., and Deitrich, R. A. (1998). Distribution and kinetics of ethanol metabolism in rat brain. Alcohol. Clin. Exp. Res. 22, 1623-1627. doi: 10.1111/j.15300277.1998 tb03958 x

Conflict of Interest Statement: The authors declare that the research was conducted in the absence of any commercial or financial relationships that could be construed as a potential conflict of interest.

Received: 30 April 2013; paper pending published: 01 June 2013; accepted: 27 June 2013; published online: 15 July 2013.

Citation: Peana AT and Acquas E (2013) Behavioral and biochemical evidence of the role of acetaldehyde in the motivational effects of ethanol. Front. Behav. Neurosci. 7:86. doi: 10.3389/ fnbeh.2013.00086

Copyright (c) 2013 Peana and Acquas. This is an open-access article distributed under the terms of the Creative Commons Attribution License, which permits use, distribution and reproduction in other forums, provided the original authors and source are credited and subject to any copyright notices concerning any third-party graphics etc. 